\title{
Analytical solution for static bending analysis of functionally graded plates with porosities
}

\author{
Slimane Merdaci \\ University of Sidi Bel Abbes, Faculty of Technology, Civil Engineering and Public Works Department, BP 89 Cité Ben M'bidi \\ 22000 Sidi Bel Abbes, Algeria. \\ slimanem2016@gmail.com,bttp://orcid.org/0000-0001-8221-3760
}

\author{
Adda Hadj Mostefa \\ University of Rélizane, Institut des Sciences \& Technologie, Rélizane, Algeria. \\ badj9510@gmail.com
}

\section{Youcef Beldjelili, Mohamed Merazi, Sabrina Boutaleb, Hadjira Hellal \\ University of Sidi Bel Abbes, Faculty of Technology, Civil Engineering and Public Works Department, Algeria. beldjelili.youcef@gmail.com,merazi@botmail.com,sabrinasbouta@gmail.com, hadjirambell@gmail.com}

ABSTRACT. The paper examines a static bending of porous functional plates (FGP) and rectangular plate solutions, based on an underlying high-order shear deformation theory. The proposed high-order shear deformation theory, as opposed to other theories, includes four unknowns. For this reason, a new shear strain function is considered. The technique of Navier is used in closed-form FGP solutions. Results of deflections and stresses are presented for simply supported border conditions. Current figures are contrasted with the non-poreous plate deflecting solutions and the literature's stresses. Effects of different parameters, including thickness, gradient index and porosity of FGM plates, are discussed.

KEYwORDS. FGP; Static bending; Power-law; Porosity factor; High-order theory.

\section{OPEN $\bigcirc$ ACCESS}

Citation: Merdaci, S., Hadj Mostefa, A., Beldjelili, Y., Merazi, M., Boutaleb, S., Hellal, H., Analytical solution for static bending analysis of functionally graded plates with porosities, Frattura ed Integrità Strutturale, 55 (2021) 65-75.

Received: 12.09 .2020

Accepted: 15.10 .2020

Published: 01.01.2021

Copyright: (C) 2021 This is an open access article under the terms of the CC-BY 4.0, which permits unrestricted use, distribution, and reproduction in any medium, provided the original author and source are credited.

\section{INTRODUCTION}

7 hese materials are generally recognized and produced in many foreign science labs, and one of the most widely used composites gives various fields such as engineering, the aeronautics, chemical, nuclear energy, electronics , optics, civil engineering, biomaterials, etc. [1-4]. The materials used in this field are functionally graded materials (FGMs). The material compositions of FGMs are assumed to vary smoothly and continuously in all gradient directions. In the mid 1980s, Japanese scientists developed the earliest FGMs as high-temperature-resistant materials for aerospace applications. During the sintering process and in the production of FGM porosity, materials may occur. This porosity is 
because of the large temperature coagulation difference between the material components [5]. The porosities in ref [6] are identified in lateral FGM samples with multi-stage sequence filtration. It is thus critical that the porosity effect is taken into account when designing FG dynamic load components.

The most popular of these theories are classic platform theory (CPT), the theory of first plate order (FSDT) and refined plate theory (RPT). The Kirchhoff Love hypothesis is based on the classical plate theory (CLPT) [7-9], an extension of the traditional plate theory (CPT), this model is provides acceptable results for the analysis of plates thin and neglect Normal deformation and transverse shear results. Both Reissner [10] and Mindlin [11] used the FSDPT (first-order sharp deformation theories) and accounted for the cross-sectional shear effects through simple linear differences in in-ground thickness shifts. The correction factor is not appropriate for this model, refined plate theory (RPT) and higher order theories of shear deformation (HSDT) are responsible for shear deformation effects and stress-free boundary conditions. For decades, a large number of RPT and HSDTs have been proposed with a particular number of unknowns [12-20].

A great number of analysis and complex platform hypotheses were recently suggested to study the conduct of mechanical FGM plates. Information concerning the study of static bending is especially important for the optimal design of structures. A new, higher order sharp theory of deformation (HSDT) is used in the study of the bending and free vibration of multi-layered panels and coats [21]. The rectangular bending motion on plate, which is supported only on four sides (FGM), has been studied more and more during recent years, subject to transverse static loading, with a refined shear deformation theory in high order [22-26]. It is proposed to study twin (2D) and quasi-3D (sometimes 3D) functionally graded plates to bend and free vibration using hyperbolic HSDT function [27].

The literature reviews on porosity effect are presented by several researchers in the recent works on porosity effect of FGM plates and beams. The effect of porosity is therefore important to consider in the design of static and bending plates made of functionally graded materials FGM [28-33] and sandwich plates FGM with porosity Usage [33-35] of a high-order shear-deformation theory. Consequently, studies focused more and more on the dynamic and free vibration of plate made of functionally graded FGM materials in recent years [37-47]. The dynamic fracture behavior of homogeneous and functionally graded materials under dynamic loading [48] and the investigating damage of functionally graded particulate materials by means of a multiscale approach based on micromechanics principles [49].

This paper aims to present a research solution for the performance of static porosity-grading plates analysis using highorder shear deformation theory. During the manufacture of these plates, defects such as porosities may appear, considering the porosities that can occur inside the functionally graded materials (FGM) plates. The board is called a porous board according to the power law on volume fractions of the platform elements, the Poisson ratio is constant. The Navier solution in closed-form is used to correct the limit conditions of simply supported FG pourer boards. The Navier solution is also used. This theory removes the effect of shear correction factors on the plates and follows the equilibrium conditions of the porous FGM layer. The results of the current theory of the porous FGM plates are studied as well as the effect of the aspect ratio, the thickness ratio, the scaled exponent factor, and the deflection and stress porosity. In the assessment of deflations and stress distribution of functionally classified material plates, the impact of porosity on shave deformation has been increased.

\section{THEORY AND FORMULATIONS}

onsider a rectangular, wide FG-platform with length (a), width (b) and thickness (h) of a given functional material as shown in Fig. 1.

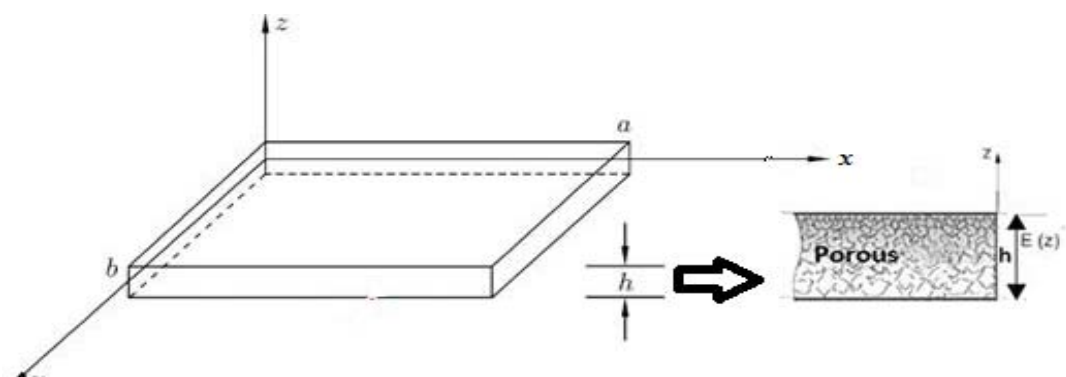

Figure 1: Geometry and FG porous plate coordinates. 
The FGM plate is subjected to a transverse load $q(x, y)$ for deformation analysis of the plate and a rectangular cartesian $\mathrm{X}$ and Y co-ordinates are attached. The analysed plate is bounded by coordination levels $(x=0, a)$ and $(y=0, b)$. Let the present platform be transformed by exponential or polynomial law from lower to upper surfaces. First and foremost, we will look at a non-homogeneity material with a porosity volumetric function, namely, $\xi(0 \leq \xi \leq 1)$.

The functional relation for the ceramic and metal FGM plates between $E(z)$ is assumed.

$$
E(z)=\left(E_{c}-E_{m}\right)\left(\frac{1}{2}-\frac{z}{h}\right)^{p}+E_{m}-\left(E_{c}+E_{m}\right) \frac{\xi}{2}
$$

When $E_{c}$ and $E_{m}$ are the corresponding ceramic and metal elements, and " $P$ " is an exponent volume fraction that takes values greater or equal to zero. The above power law theory demonstrates a simple blending rule used to achieve the efficient characteristics of a ceramic metal platform.

The theory of shear deformation plates is ideal for displacements in this study:

$$
\begin{gathered}
u(x, y, z)=u_{0}(x, y)-z \frac{\partial w_{b}}{\partial x}-f(z) \frac{\partial w_{s}}{\partial x} \\
v(x, y, z)=v_{0}(x, y)-z \frac{\partial w_{b}}{\partial y}-f(z) \frac{\partial w_{s}}{\partial y} \\
w(x, y, z)=w_{b}(x, y)+w_{s}(x, y)
\end{gathered}
$$

In the present theory, this function $f(\mathcal{z})$ is considered:

$$
f(z)=z-\sin \left(\frac{\pi z}{b}\right)+\frac{\pi}{2 h} z
$$

With the small strain assumptions, the strain-displacement relation is given by the following equation:

$$
\begin{aligned}
& \varepsilon_{x}=\varepsilon_{x}^{0}+z k_{x}^{b}+f(z) k_{x}^{s}, \varepsilon_{y}=\varepsilon_{y}^{0}+z k_{y}^{b}+f(z) k_{y}^{s}, \varepsilon_{z}=0 \\
& \gamma_{x y}=\gamma_{x y}^{0}+z k_{x y}^{b}+f(z) k_{x y}^{s}, \gamma_{y z}=g(z) \gamma_{y z}^{s}, \gamma_{x z}=g(z) \gamma_{x z}^{s} \\
& \left\{\begin{array}{l}
\varepsilon_{x}^{0} \\
\varepsilon_{y}^{0} \\
\gamma_{x y}^{0}
\end{array}\right\}=\left\{\begin{array}{l}
\frac{\partial u_{0}}{\partial x} \\
\frac{\partial v_{0}}{\partial y} \\
\frac{\partial u_{0}}{\partial y}+\frac{\partial v_{0}}{\partial x}
\end{array}\right\},\left\{\begin{array}{l}
k_{x}^{b} \\
k_{y}^{b} \\
k_{x y}^{b}
\end{array}\right\}=\left\{\begin{array}{l}
-\frac{\partial^{2} w_{b}}{\partial x^{2}} \\
-\frac{\partial^{2} w_{b}}{\partial y^{2}} \\
-2 \frac{\partial^{2} w_{b}}{\partial x \partial y}
\end{array}\right\},\left\{\begin{array}{l}
k_{x}^{s} \\
k_{y}^{s} \\
k_{x y}^{s}
\end{array}\right\}=\left\{\begin{array}{l}
\frac{\partial^{2} w_{s}}{\partial x^{2}} \\
\frac{\partial^{2} w_{s}}{\partial y^{2}} \\
2 \frac{\partial^{2} w_{s}}{\partial x \partial y}
\end{array}\right\},\left\{\begin{array}{l}
\gamma_{y z}^{s} \\
\gamma_{x z}^{s}
\end{array}\right\}=\left\{\begin{array}{c}
\frac{\partial w_{s}}{\partial y} \\
\frac{\partial w_{s}}{\partial x}
\end{array}\right\}, g(z)=1-\frac{d f(z)}{d z}
\end{aligned}
$$

The constituent relationships can be written as elastic and isotropic FGMs

$$
\left\{\begin{array}{l}
\sigma_{x} \\
\sigma_{y} \\
\tau_{x y}
\end{array}\right\}=\left[\begin{array}{ccc}
Q_{11} & Q_{12} & 0 \\
Q_{12} & Q_{22} & 0 \\
0 & 0 & Q_{66}
\end{array}\right]\left\{\begin{array}{l}
\varepsilon_{x} \\
\varepsilon_{y} \\
\gamma_{x y}
\end{array}\right\},\left\{\begin{array}{l}
\tau_{y z} \\
\tau_{z x}
\end{array}\right\}=\left[\begin{array}{cc}
Q_{44} & 0 \\
0 & Q_{55}
\end{array}\right]\left\{\begin{array}{l}
\gamma_{y z} \\
\gamma_{z x}
\end{array}\right\}
$$

Using the material properties, the coefficients of stiffness, $Q i j$, can be expressed 


$$
Q_{11}=Q_{22}=\frac{E(z)}{1-v^{2}}, Q_{12}=\frac{v E(z)}{1-v^{2}}, Q_{44}=Q_{55}=Q_{66}=\frac{E(z)}{2(1+v)}
$$

The static equations can be solved by virtual displacement. It may be classified as analysis

$$
\int_{-b / 2}^{b / 2} \int_{\Omega}\left[\sigma_{x} \delta \varepsilon_{x}+\sigma_{y} \delta \varepsilon_{y}+\tau_{x y} \delta \gamma_{x y}+\tau_{y z} \delta \gamma_{y z}+\tau_{x z} \delta \gamma_{x z}\right] d \Omega d z-\int_{\Omega} q \delta W d \Omega=0
$$

The top surface. Where the results of stress $N, M$ and $S$ are described by:

$$
\begin{aligned}
& \left\{\begin{array}{lll}
N_{x}, & N_{y}, & N_{x y} \\
M_{x}^{b}, & M_{y}^{b}, & M_{x y}^{b} \\
M_{x}^{s}, & M_{y}^{s}, & M_{x y}^{s}
\end{array}\right\}=\int_{-b / 2}^{b / 2}\left(\sigma_{x}, \sigma_{y}, \tau_{x y}\right)\left\{\begin{array}{c}
1 \\
z \\
f(z)
\end{array}\right\} d z, \\
& \left(S_{x z}^{s}, S_{y z}^{s}\right)=\int_{-b / 2}^{b / 2}\left(\tau_{x z}, \tau_{y z}\right) g(z) d z .
\end{aligned}
$$

The stress result is given as

$$
\begin{aligned}
& \left\{\begin{array}{l}
N \\
M^{b} \\
M^{s}
\end{array}\right\}=\left[\begin{array}{ccc}
A & B & B^{s} \\
A & D & D^{s} \\
B^{s} & D^{s} & H^{s}
\end{array}\right]\left\{\begin{array}{c}
\varepsilon \\
k^{b} \\
k^{s}
\end{array}\right\}, S=A^{s} \gamma \\
& N=\left\{N_{x}, N_{y}, N_{x y}\right\}^{t}, M^{b}=\left\{M_{x}^{b}, M_{y}^{b}, M_{x y}^{b}\right\}^{t}, M^{s}=\left\{M_{x}^{s}, M_{y}^{s}, M_{x y}^{s}\right\}^{t} \\
& \varepsilon=\left\{\varepsilon_{x}^{0}, \varepsilon_{y}^{0}, \gamma_{x y}^{0}\right\}^{t}, k^{b}=\left\{k_{x}^{b}, k_{y}^{b}, k_{x y}^{b}\right\}^{t}, k^{s}=\left\{k_{x}^{s}, k_{y}^{s}, k_{x y}^{s}\right\}^{t} \\
& A=\left[\begin{array}{ccc}
A_{11} & A_{12} & 0 \\
A_{12} & A_{22} & 0 \\
0 & 0 & A_{66}
\end{array}\right], B=\left[\begin{array}{ccc}
B_{11} & B_{12} & 0 \\
B_{12} & B_{22} & 0 \\
0 & 0 & B_{66}
\end{array}\right], D=\left[\begin{array}{ccc}
D_{11} & D_{12} & 0 \\
D_{12} & D_{22} & 0 \\
0 & 0 & D_{66}
\end{array}\right] \\
& B^{s}=\left[\begin{array}{ccc}
B_{11}^{s} & B_{12}^{s} & 0 \\
B_{12}^{s} & B_{22}^{s} & 0 \\
0 & 0 & B_{66}^{s}
\end{array}\right], D^{s}=\left[\begin{array}{ccc}
D_{11}^{s} & D_{12}^{s} & 0 \\
D_{12}^{s} & D_{22}^{s} & 0 \\
0 & 0 & D_{66}^{s}
\end{array}\right], H^{s}=\left[\begin{array}{ccc}
H_{11}^{s} & H_{12}^{s} & 0 \\
H_{12}^{s} & H_{22}^{s} & 0 \\
0 & 0 & H_{66}^{s}
\end{array}\right] \\
& S=\left\{S_{x z}^{s}, S_{y z}^{s}\right\}^{t}, \gamma=\left\{\gamma_{x z}, \gamma_{y z}\right\}^{t}, A^{s}=\left[\begin{array}{cc}
A_{44}^{s} & 0 \\
0 & A_{55}^{s}
\end{array}\right]
\end{aligned}
$$

where $A i j, B i j$, etc is defined as plate stiffness 


$$
\begin{aligned}
& \left\{A_{i j}, B_{i j}, D_{i j}\right\}=\int_{-b / 2}^{b / 2}\left(1, z, z^{2}\right) Q_{i j} d z \quad(i, j=1,2,6) \\
& \left\{B_{i j}^{s}, D_{i j}^{s}, H_{i j}^{s}\right\}=\int_{-b / 2}^{b / 2}\left(f(z), z f(z), f^{2}(z)\right) Q_{i j} d z \quad(i, j=1,2,6) \\
& \left\{A_{i j}^{s}\right\}=\int_{-b / 2}^{b / 2}\left([g(z)]^{2}\right) Q_{i j} d z, \quad(i, j=4,5) \\
& Q_{11}^{(n)}=\frac{E(z)}{1-v^{2}}, A_{44}^{s}=A_{55}^{s}=\sum_{n=1}^{3} \int_{b_{n}}^{b_{n+1}} \frac{E(z)}{2(1+v)}[g(z)]^{2} d z
\end{aligned}
$$

Thus the balance equations associated with the newest shear deformation theory can be obtained,

$$
\begin{aligned}
& \delta u: \quad \frac{\partial N_{x}}{\partial x}+\frac{\partial N_{x y}}{\partial y}=0 \\
& \delta v: \quad \frac{\partial N_{x y}}{\partial x}+\frac{\partial N_{y}}{\partial y}=0 \\
& \delta w_{b}: \quad \frac{\partial^{2} M_{x}^{b}}{\partial x^{2}}+2 \frac{\partial^{2} M_{x y}^{b}}{\partial x \partial y}+\frac{\partial^{2} M_{y}^{b}}{\partial y^{2}}+q=0 \\
& \delta w_{s}: \quad \frac{\partial^{2} M_{x}^{s}}{\partial x^{2}}+2 \frac{\partial^{2} M_{x y}^{s}}{\partial x \partial y}+\frac{\partial^{2} M_{y}^{s}}{\partial y^{2}}+\frac{\partial S_{x x}^{s}}{\partial x}+\frac{\partial S_{y z}^{s}}{\partial y}+q=0
\end{aligned}
$$

\section{FG PLATES ANALYTICAL SOLUTIONS}

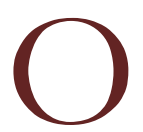

$\mathrm{n}$ the side edges of the FG plate are placed the following easily endorsed boundary conditions:

$$
\begin{aligned}
& v_{0}=w_{b}=w_{s}=\frac{\partial w_{b}}{\partial y}=\frac{\partial w_{s}}{\partial y}=N_{x}=M_{x}^{b}=M_{x}^{s}=0 \text { and } x=0, a \\
& u_{0}=w_{b}=w_{s}=\frac{\partial w_{b}}{\partial x}=\frac{\partial w_{s}}{\partial x}=N_{y}=M_{y}^{b}=M_{y}^{s}=0 \text { and } y=0, \quad b
\end{aligned}
$$

The external force can be expressed as per the Navier solution:

$$
q(x, y)=\sum_{m=1}^{\infty} \sum_{n=1}^{\infty} q_{m n} \sin (\lambda x) \sin (\mu y)
$$

where $\lambda=m \pi / a$ and $\mu=n \pi / b, \ll m »$ and $« n »$ are mode numbers. Where $q_{0}$ represents the intensity of the load at the plate center.

For the case of a sinusoidal distributed load, we have

$$
Q_{11}=q_{0}, m=n=1
$$


We consider the following solution form $\left(u, v, w_{b}, w_{s}\right)$, following the Navier solution protocol, to satisfy the boundary conditions

$$
\left\{\begin{array}{c}
u \\
v \\
w_{b} \\
w_{s}
\end{array}\right\}=\left\{\begin{array}{c}
U_{m m n} \cos (\lambda x) \sin (\mu y) \\
V_{m n n} \sin (\lambda x) \cos (\mu y) \\
W_{b m n} \sin (\lambda x) \sin (\mu y) \\
W_{s m n} \sin (\lambda x) \sin (\mu y)
\end{array}\right\}
$$

where the parameters $U_{m n n}, V_{m n,} W_{b m n}$ and $W_{s m n}$ are arbitrary. First order equations system as:

$$
[K]\{\Delta\}=\{F\}
$$

where the $\{\Delta\}$ and $\{F\}$ columns are referred to

$$
\begin{aligned}
& \{\Delta\}^{T}=\left\{U_{m n}, V_{m n}, W_{b m n}, W_{s m n}\right\},\{F\}^{T}=\left\{0,0,-q_{m n},-q_{m n}\right\} \\
& {[K]=\left[\begin{array}{llll}
a_{11} & a_{12} & a_{13} & a_{14} \\
a_{12} & a_{22} & a_{23} & a_{24} \\
a_{13} & a_{23} & a_{33} & a_{34} \\
a_{14} & a_{24} & a_{34} & a_{44}
\end{array}\right]}
\end{aligned}
$$

The elements $a_{i j}=a_{j i}$ of the coefficient matrix $[\mathrm{K}]$.

\section{NUMERICAL RESULTS AND DISCUSSIONS}

umerical results for changes and stresses in functionally graded porosity plates are given in this section in order to confirm the exactness of the present formulation. The material properties of the FG plates are aluminum and alumina:

- Metal (Aluminum, $\mathrm{Al}): \mathrm{E}_{\mathrm{m}}=70 \mathrm{GPa}, \nu=0.3$.

- Ceramic (Alumina, $\mathrm{Al}_{2} \mathrm{O}_{3}$ ): $\mathrm{E}_{\mathrm{c}}=380 \mathrm{GPa}, \nu=0.3$.

The following non-dimensional parameters are used for simplicity:

$$
\bar{w}=\frac{10 h E_{c}}{a^{2} q_{0}} w\left(\frac{a}{2}, \frac{b}{2}\right), \bar{\sigma}_{x}=\frac{10 b^{2}}{a^{2} q_{0}} \sigma_{x}\left(\frac{a}{2}, \frac{b}{2}, \frac{b}{2}\right), \bar{\tau}_{x x}=\frac{b}{a q_{0}} \tau_{x z}\left(0, \frac{b}{2}, 0\right)
$$

Thicknesses coordinate $\bar{z}=q / h$.

Tab. 1, dimensionalless deflection $(a / h=10)$, normal square FG plate transverse stress $(a=b=1)$ and separate Power-law index values $p$, higher-order shear deformation theory four uncertain predictions in relation to the theory of Zenkour [50] and refined plate theory (RPT) Hadj Henni et al [20] in the literature. The inclusion of the coefficient of porosity $(\xi=0)$ is not included in Tab. 1. Displacements and stresses resulting from the new theory are found to be in excellent agreement with Zenkour [50] and Hadj Henni et al [20] RPT theories. Furthermore, Tab. 1 indicates that the shifts increase with the increase of the power-law indices when the plates are made from either fully ceramic $(p=0)$ or fully metal $(p=\infty)$ normal stress and transverse normal stress are similar. This is due to the increased power law index, which makes FG plate more flexible, that is to say decreases its rigidity.

Fig. 2 shows non-dimensional displacement differences for two thickness ratios $(\mathrm{a} / \mathrm{h}=10$ and $\mathrm{a} / \mathrm{h}=20)$ based on the power and law index " $p$ " for the perfect floor $(\xi=0)$ and the three porosity values $(\xi=0.1,0.2$ and 0.3$)$ From this curve, 
it can be concluded that the dimensional transition is the with the rise in the force law index. Moreover, increasing the porosity coefficient increases the dimensional displacement of the two thickness ratios.

\begin{tabular}{cccccccccc}
\hline $\boldsymbol{9}$ & $\bar{w}$ & \multicolumn{3}{c}{$\bar{\sigma}_{x}$} & & & $\bar{\tau}_{x z}$ \\
Ceramic & Zenkour[50] & RPT[20] & Present & Zenkour[50] & RPT[20] & Present & Zenkour[50] & RPT[20] & Present \\
1 & 0.2960 & 0.2961 & $\mathbf{0 . 2 9 6 0 3}$ & 1.9955 & 1.9943 & $\mathbf{1 . 9 9 5 5}$ & 0.2462 & 0.2386 & $\mathbf{0 . 2 2 0 5}$ \\
2 & 0.5889 & 0.5890 & $\mathbf{0 . 5 8 8 9 1}$ & 3.0870 & 3.0850 & $\mathbf{3 . 0 8 5 0}$ & 0.2462 & 0.2386 & $\mathbf{0 . 2 3 6 9}$ \\
3 & 0.7573 & 0.7573 & $\mathbf{0 . 7 5 7 3 3}$ & 3.6094 & 3.6067 & $\mathbf{3 . 6 0 6 7}$ & 0.2265 & 0.2186 & $\mathbf{0 . 2 2 4 9}$ \\
4 & 0.8377 & 0.8375 & $\mathbf{0 . 8 3 7 6 8}$ & 3.8742 & 3.8709 & $\mathbf{3 . 8 7 0 9}$ & 0.2107 & 0.2024 & $\mathbf{0 . 2 1 0 5}$ \\
5 & 0.8819 & 0.8816 & $\mathbf{0 . 8 8 1 8 7}$ & 4.0693 & 4.0655 & $\mathbf{4 . 0 6 5 5}$ & 0.2029 & 0.1944 & $\mathbf{0 . 1 9 8 4}$ \\
10 & 0.9118 & 0.9112 & $\mathbf{0 . 9 1 1 8 3}$ & 4.2488 & 4.2447 & $\mathbf{4 . 2 4 4 7}$ & 0.2017 & 0.1930 & $\mathbf{0 . 1 8 9 8}$ \\
Metal & 1.0089 & 1.0085 & $\mathbf{1 . 0 0 8 9 2}$ & 5.0890 & 5.0849 & $\mathbf{5 . 0 8 4 9}$ & 0.2198 & 0.2114 & $\mathbf{0 . 1 9 8 6}$ \\
& 1.6070 & 1.6074 & $\mathbf{1 . 6 0 7 0 2}$ & 1.9955 & 1.9943 & $\mathbf{1 . 9 9 4 3}$ & 0.2462 & 0.2386 & $\mathbf{0 . 2 2 0 5}$ \\
\hline
\end{tabular}

Table 1: Functionally graded plate FG with non-dimensional deflections and stresses on various power law index.
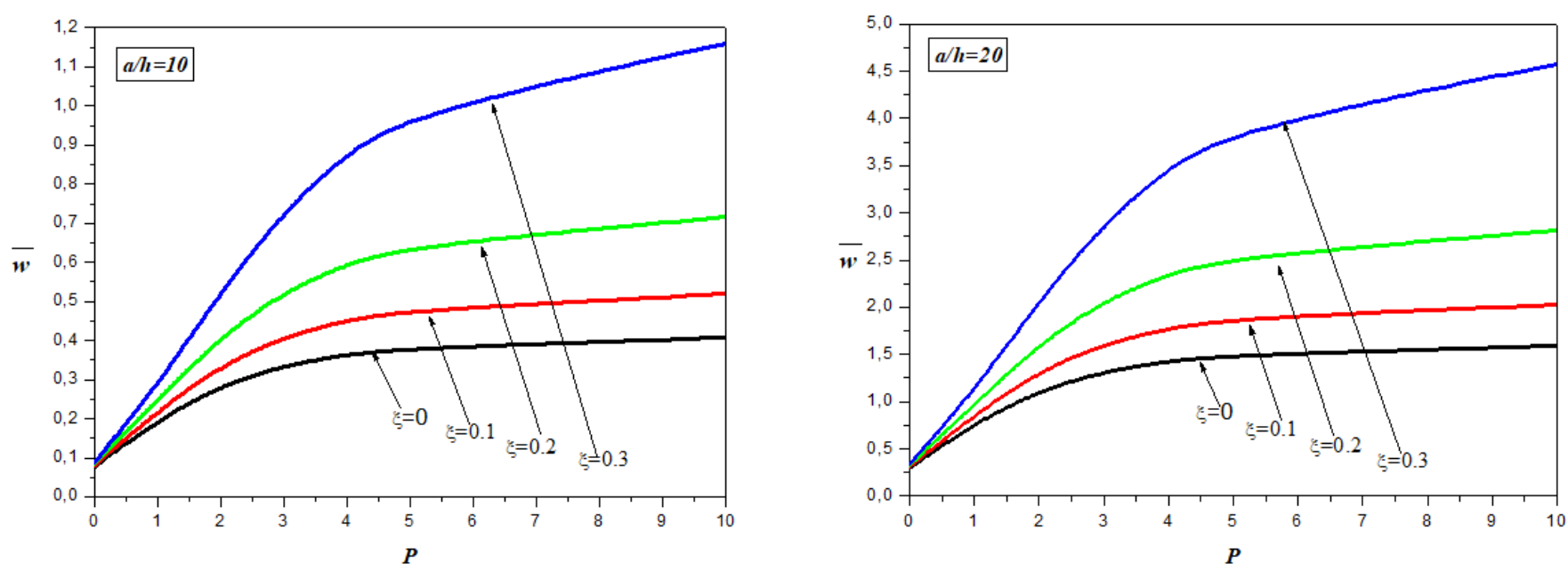

Figure 2: Displacement variation as a function of the power index " $p$ " and the volume fraction of porosity of a FG plate.

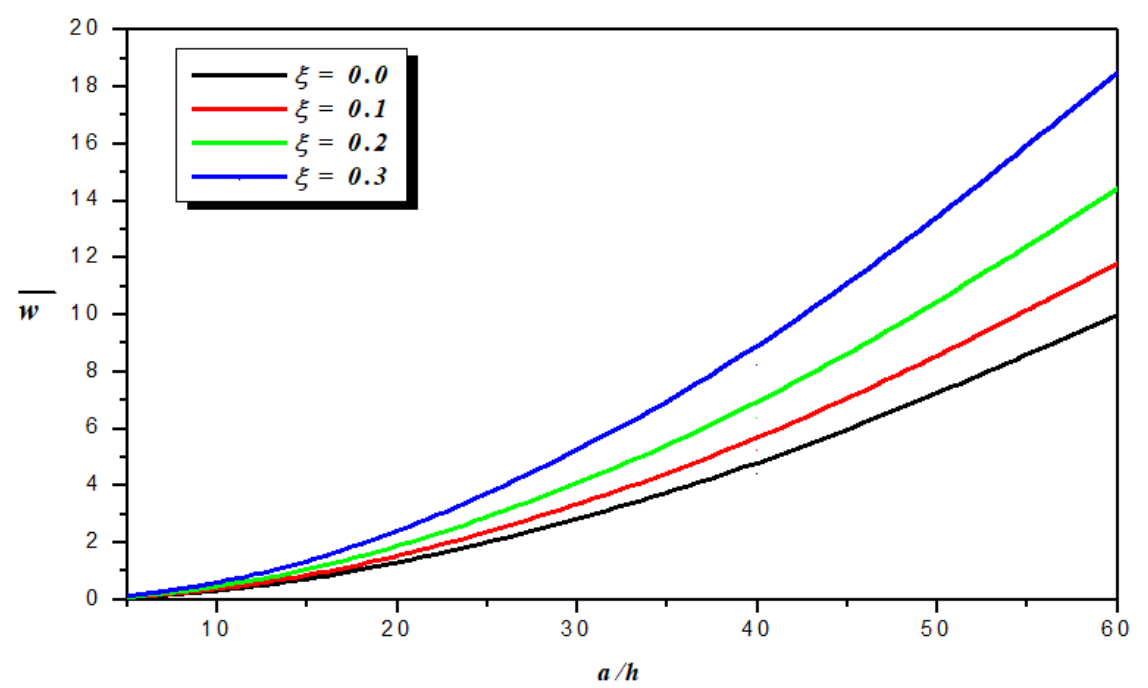

Figure 3: Displacement Variation depending on the thickness ratio $(\mathrm{a} / \mathrm{h})$ for various porosity factor values $\xi$. 
Fig. 3 illustrates the influence of the aspect ratio $(\mathrm{a} / \mathrm{h})$ for the fluidization of the FG plate for perfect plate size $(\xi=0)$, and three values of the imperfect plates of the porosity coefficient $(\xi=0.1,0.2$ and 0.3$)$. It is assumed the power-law index to be constant, $p=2$. The increase in dimensional displacements, explained through the effect of material rigidity, i.e. the rise of the value of the porosity coefficient $(\xi)$ is seen in this figure, leads to an increase in plate displacements. The impact of porosity on the bending of a plate has also been shown to increase with the larger values of the ratio of thickness to length.

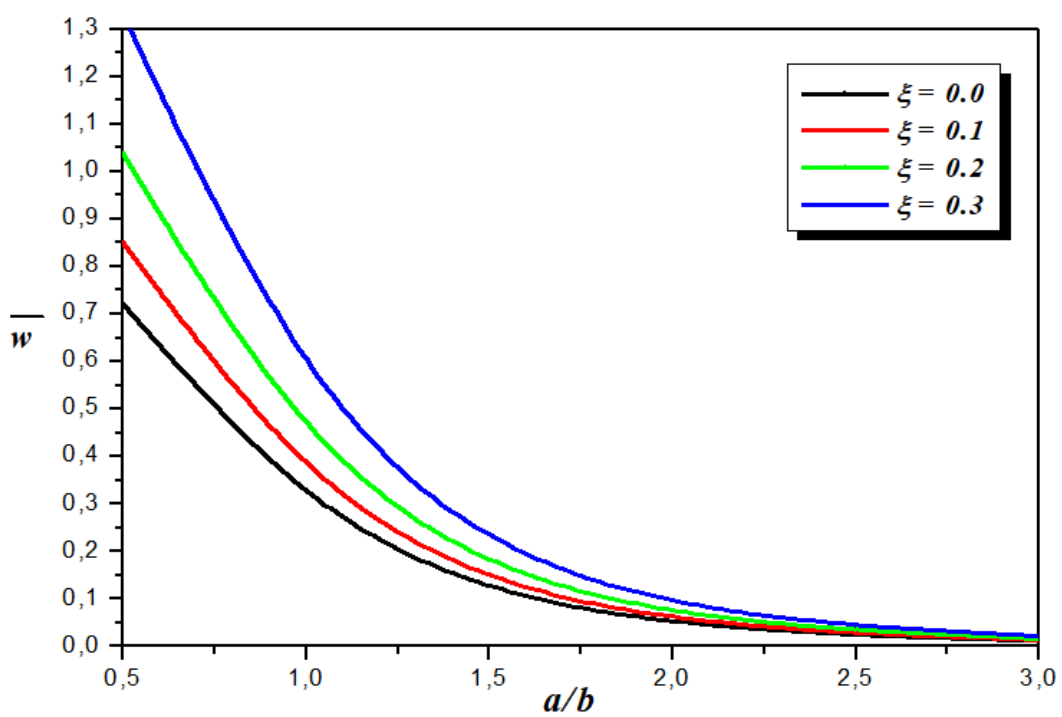

Figure 4: Displacement variance as a geometric ratio feature (a / b) for different porosity factor values $(\xi)$.

In Fig. 4, we study a dimensionless Displacement variation function as a geometric ratio of square ( $a=b=1)$ and rectangular $(a \neq b)$ FGP, as well as of the different porosity coefficient values $(\xi=0.1,0.2$ and 0.3$)$, with equal density ratio $(\mathrm{a} / \mathrm{h}=10)$ and a material index $p=2$. We found a decrease in that ratio reduces displacement.

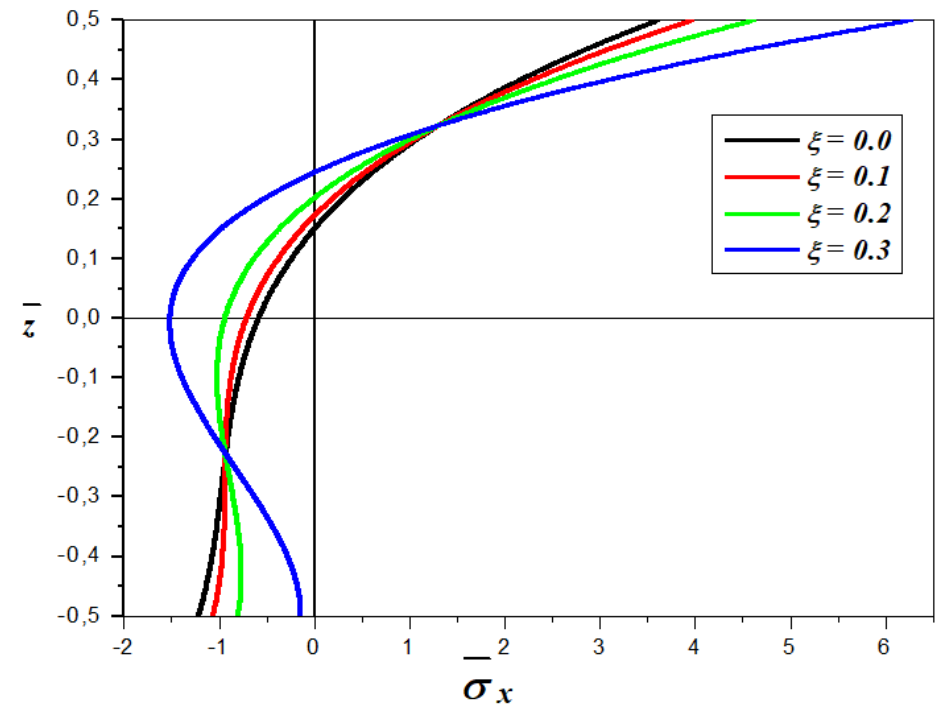

Figure 5: The thickness of FGP axial stress distribution for different porosity factor $(\xi)(\mathrm{a} / \mathrm{h}=10$ and $p=2)$.

Fig. 5 took account of the effect of the porosity of the FGP by adding the coefficient ( $\xi$ ). Therefore, four values are maintained $(\xi=0,0.1,0.2$ and 0.3$)$. The increase in the porosity index $(\xi)$ can be observed to contribute to increased stress. This can be explained by the reduction of the rigidity of the plate by the porosity. The stresses are tensile above the middle plane and compressed under the middle plane. It should be remembered that the overall stress based on the magnitude of the volume fraction exponent. Fig. 6 indicates shear stresses through the transverse thickness distribution. 
This figure shows the remarkable direct impact of the porosity effect; this occurs at a point in the FGP middle plane and lowers transverse shear stress.

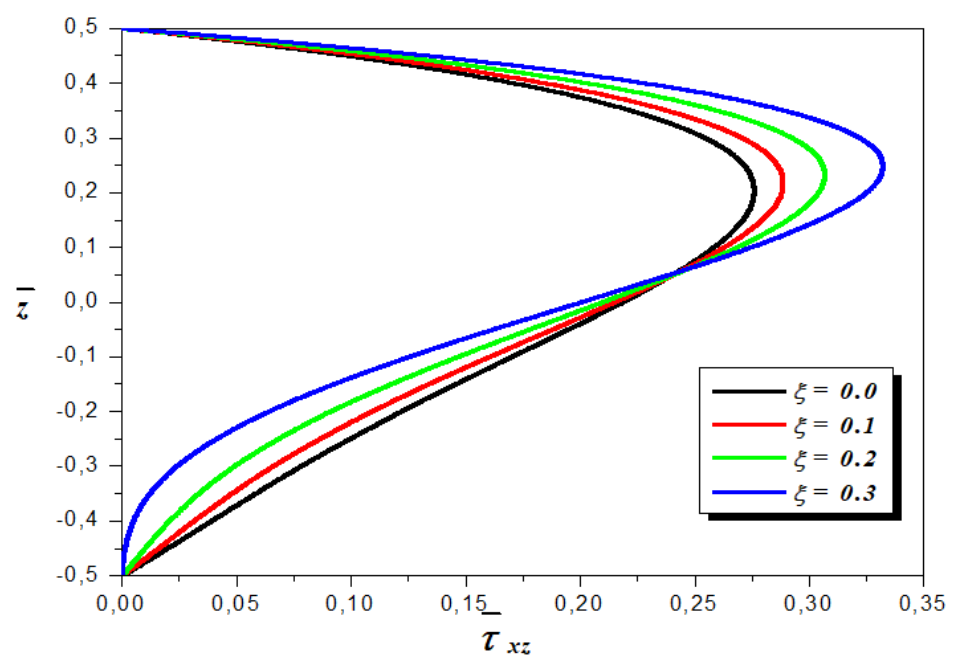

Figure 6: Via the thickness distributions of the FG shear stress $(\mathrm{a} / \mathrm{h}=10$ and $p=2)$.

\section{CONCLUSION}

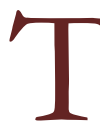
he paper is intended to analyses the static bending effect of functionally labeled plates with porosities that can occur inside of this type of plates based on the concept of high order shear deformation. Analytical solutions with realistic grades for porous and rectangular plates are given. This paper supports study and the analysis of various parameters, such as the material parameter, volume fraction, appearance ratio, surface thickness and coefficient of porosity. The control equations are resolved with the Navier-style closed-form solution for sinusoidal FG plates. The material characteristics vary in the thickness direction of the sheet according to the rules of the mixture and are reformulated to approximate the material characteristics in the phased porosity. The results from the static bending study for this test are fully validated by the observations present and those present in the literature. There is discussion of the use of graded and porosity parameters. From this work, we can say that the current and simple theory of the resolution of the mechanical behavior of porosity FGM plates that defect factories.

\section{REFERENCES}

[1] Suresh, S., Mortensen, A. (1998). Fundamental of functionally graded materials. London: Maney.

[2] Hadj Mostefa, A., Merdaci, S., and Mahmoudi, N. (2018). An Overview of Functionally Graded Materials «FGM», Proceedings of the Third International Symposium on Materials and Sustainable Development, ISBN 978-3-31989706-6, pp. 267-278.

[3] Paulino, G. H., and Nelli Silva, E. C. (2005). Design of Functionally Graded Structures Using Topology Optimization, Materials Science Forum 492-493, pp. 435-440. DOI: 10.4028/www.scientific.net/MSF.492-493.435.

[4] Paulino, G.H., Jin, Z.-H. and Dodds, Jr.R.H. (2003). Failure of Functionally Graded Materials, Comprehensive Structural Integrity, Volume 2, (ISBN: 0-08-044156-4), pp. 607-644.

[5] Zhu, J., Lai, Z., Yin, Z., Jeon, J., Lee, S. (2001). Fabrication of ZrO2-NiCr functionally graded material by powder metallurgy, Mater Chem Phys, 68, pp. 130-135.

[6] Wattanasakulpong, N., Prusty, B.G., Kelly, D.W., Hoffman, M. (2012). Free vibration analysis of layered functionally graded beams with experimental validation, Mater Des, 36, pp. 182-190.

[7] Reissner, E., and Stavsk, Y. (1961). Bending and stretching of certain types of heterogeneous aelotropic elastic plates, ASME J ApplMech, 28, pp. 402-428.

[8] Timoshenko, S.P., and Gere, J.M. (1972). Mechanics of Materials, New York: D.Van Nostrand Company. 
[9] Reddy, J.N., Wang, C.M. (2000). An overview of the relationships between solutions of the classical and shear deformation plate theories, Compos. Sci. Technol, 60, pp. 2327-2335.

[10] Reissner, E. (1945). The effect of transverse shear deformation on the bending of elastic plates. Trans. ASME J. Appl. Mech, 12, pp. 69-77.

[11] Mindlin, R.D. (1951). Influence of rotary inertia and shear on flexural motions of isotropic, elastic plates, Trans. ASME J. Appl.Mech, 18, pp. 31-38.

[12] Reddy, J.N. (1984). A simple higher-order theory for laminated composite plates, Trans. ASME J. Appl. Mech, 51, 745-752.

[13] Ren, J.G. (1986). A new theory of laminated plate, Compos. Sci. Technol, 26, pp. 225-239.

[14] Kant, T., Pandya, B.N. (1988). A simple finite element formulation of a higher-order theory for unsymmetrically laminated composite plates, Compos. Struct, 9, pp. 215-264.

[15] Mohan, P.R., Naganarayana, B.P., Prathap, G. (1994), Consistent and variational correct finite elements for higherorder laminated plate theory, Compos. Struct, 29, pp. 445-456.

[16] Kim, S.E., Thai, H.T., Lee, J. (2009). Atwo variable refined plate theory for laminated composite plates, Compos. Struct, 89, pp. 197-205.

[17] Merdaci, S., Tounsi, A., Houari, M.S.A., Mechab, I., Hebali, H., Benyoucef, S. (2011). Two new refined shear displacement models for functionally graded sandwich plates, Arch Appl Mech, 81, pp. 1507-1522.

[18] Reissner, E. (1944). On the theory of bending of elastic plates, J. Math. Phy, 23, pp. 184-191.

[19] Reddy, J.N., Wang, C.M., Lee, K.H. (1997). Relationships between bending solutions of classical and shear deformation beam theories, International Journal of Solids and Structures, 34 (26), pp. 3373-338.

[20] Hadj Henni, A., Ait Atmane, H., Mechab I., Boumia L., Tounsi A., Adda Bedia E.A. (2011). Static Analysis of Functionally Graded Sandwich Plates Using an Efficient and Simple Refined Theory, Chinese Journal of Aeronautics, 24, pp. 434-448. DOI: 10.1016/S1000-9361(11)60051-4

[21]Zine, A., Tounsi, A., Draiche, K., Sekkal, M., and Mahmoud, S.R. (2018). A novel higher-order shear deformation theory for bending and free vibration analysis of isotropic and multilayered plates and shells, Steel Compos. Struct, 26(2), pp. 125-137.

[22] Merdaci, S., Benyoucef, S., Tounsi, A., Adda Bedia, .E.A. (2013). Etudes A La Flexion Statique Des Plaques Epaisses En Materiaux A Gradients De Proprietes «FGM », Revue Communication Science \& technologie « COST », 12, pp. 34-41.

[23] Merdaci, S., Boutaleb, S., Hellal, H., Benyoucef, S. (2019). Analysis of Static Bending of Plates FGM Using Refined High Order Shear Deformation Theory, J. Build. Mater. Struct, 6(1), pp pp. 32-38. DOI: 10.5281/zenodo.2609306.

[24] Reddy, J. N. (1984). A simple higher-order theory for laminated composite plates, Journal of applied mechanics, 51(4), pp. $745-752$.

[25] Shi, G. (2007), A new simple third-order shear deformation theory of plates, International Journal of Solids and Structures, 44(13), pp. 4399-4417.

[26] Shimpi, R. P., \& Patel, H. G. (2006). A two variable refined plate theory for orthotropic plate analysis, International Journal of Solids and Structures, 43(22-23), pp. 6783-6799.

[27] Younsi, A., Tounsi, A., Zaoui, .F.Z., Bousahla, A., Mahmoud, .S.R. (2018). Novel quasi-3D and 2D shear deformation theories for bending and free vibration analysis of FGM plates, Geomechanics and Engineering, 14(6), pp. 519-532.

[28] Merdaci, S. (2018). Analysis of Bending of Ceramic-Metal Functionally Graded Plates with Porosities Using of High Order Shear Theory, Advanced Engineering Forum; 30, pp. 54-70.

[29] Merdaci, S., Belghoul, H. (2019). High Order Shear Theory for Static Analysis Functionally Graded Plates with Porosities, Comptes rendus Mécanique, 347(3), pp. 207-217.

[30] Merdaci, S. (2018). Analysis of Bending of Functionally Graded Plates With Porosities Using of High Order Shear Theory, Algerian Journal of Research and Technology (AJRT), 2(1), pp. 54-69.

[31] Behravan, R. A. (2018). Static analysis of non-uniform 2D functionally graded auxeticporous circular plates interacting with the gradient elastic foundations involving friction force, Aerosp Sci Technol, 76, pp. 315-339.

[32] Karama M., Afaq, K.S., Mistou, S. (2003). Mechanical behaviour of laminated composite beam by the new multilayered laminated composite structures model with transverse shear stress continuity, Int. J. Solids Structures, 40 (6), pp. 1525-1546.

[33] Kaddari, M., Kaci, A., Bousahla, A.A., Tounsi, A., Bourada, F., Tounsi, A., Adda Bedia, E.A., Al-Osta,M.A. (2020) A study on the structural behaviour of functionally graded porous plates on elastic foundation using a new quasi-3D model: Bending and Free vibration analysis, Computers and Concrete, 25(1), pp. 37-57.

DOI: $10.12989 /$ cac.2020.25.1.037 
[34] Merdaci, S., Hadj Mostefa, A. (2020). Influence of porosity on the analysis of sandwich plates FGM using of high order shear-deformation theory, Frattura ed Integrità Strutturale, 51, pp. 199-214. DOI: 10.3221/IGF-ESIS.51.16

[35] Medani, M., Benahmed, A., Zidour, M., Heireche, H., Tounsi, A., Bousahla, A.A., Tounsi, A., Mahmoud, S.R. (2019). Static and dynamic behavior of (FG-CNT) reinforced porous sandwich plate using energy principle, Steel and Composite Structures, 32(5), pp. 595-610. DOI: 10.12989/scs.2019.32.5.595

[36] Draoui, A., Zidour, M., Tounsi, A., and Adim, B. (2019). Static and dynamic behavior of nanotubes-reinforced sandwich plates using (FSDT), J. Nano Res, 57, pp. 117-135.

[37] Merdaci, S., Belmahi, S., Belghoul, H., Hadj Mostefa, A. (2019). Free Vibration Analysis of Functionally Graded Plates FG with Porosities, International Journal of Engineering Research \& Technology (IJERT), 8 (3), pp. 143-147. DOI: $10.17577 /$ IJERTV8IS030098

[38] Merdaci, S. (2019). Free Vibration Analysis of Composite Material Plates "Case of a Typical Functionally Graded FG Plates Ceramic/Metal" with Porosities, Nano Hybrids and Composites (NHC), 25, pp. 69-83.

[39] Merdaci, S (2019). Analytical solution for free vibration analysis of plates functionally graded FGP with porosities, Recueil de Mécanique, 4(2), pp. 397-408. DOI: 10.5281/zenodo.3738699.

[40] Merdaci, S., Belghoul, H., Hadj Mostefa, A., Merazi, M., Hellal, H., Boutaleb, S. (2020). Free Vibration Analysis of Advanced Composite Plates with Porosities, Algerian Journal of Research and Technology, (AJRT), 4(2), pp. 13-22. https://www.asjp.cerist.dz/en/PresentationRevue/538

[41] Merdaci, S., Hadj, M.A., Merazi, M., Belghoul, H., Hellal, H., Boutaleb, S. (2020). Effects of even pores distribution on vibrational behavior of functionally graded plate porous rectangular and square, Procedia Structural Integrity, 26, pp. 35-45.

[42] Mojahedin, A., Farzaneh, J.E., Jabbari, M. (2014). Thermal and mechanical stability of a circular porous plate with piezoelectric actuators, Acta Mech, 225, pp. 3437-3452.

[43] Shojaeefard, M.H., Googarchin, H.S., Ghadiri, M., Mahinzare, M. (2017). Micro temperature dependent FG porous plate: free vibration and thermal buckling analysis usi modified couple stress theory with CPT and FSDT, Appl Math Model, 50, pp. 633-655.

[44] Chen, D., Yang, J., Kitipornchai, S. (2017). Nonlinear vibration and postbuckling of functionally graded graphene reinforced porous nanocomposite beams, Compos Sci Technol, 142, pp. 235-245.

[45] Kitipornchai. S., Chen, D., Yang, J. (2017). Free vibration and elastic buckling of functionally graded porous beams reinforced by graphene platelets, Mater Des, 116, pp. 656-665.

[46] Yang, J., Chen, D., Kitipornchai, S. (2018). Buckling and free vibration analyses of functionally graded graphene reinforced porous nanocomposite plates based on Chebyshev-Ritz method, Compos Struct, 193, pp. 281-294.

[47] Bhimaraddi, A., Stevens, L.K. (1984). A higher order theory for free vibration of orthotropic, homogeneous and laminated rectangular plates, Trans. ASME J. Appl. Mech, 51, pp. 195-198.

[48] Zhang, Z., Paulino, G.H. (2005). Cohesive zone modeling of dynamic failure in homogeneous and functionally graded materials, International Journal of Plasticity, 21, pp. 1195-1254. DOI: 10.1016/j.ijplas.2004.06.009.

[49] Paulino, G. H., Yin, H. M. and Sun, L. Z. (2006). Micromechanics-based interfacial debonding model for damage of functionally graded materials with particle interactions, International Journal of Damage Mechanics, pp. 1-22. DOI: $10.1177 / 1056789505060756$.

[50] Zenkour, A.M. (2006). Generalized shear deformation theory for bending analysis of functionally graded plates. Appl. Math. Model, 30, pp. 67-84. 